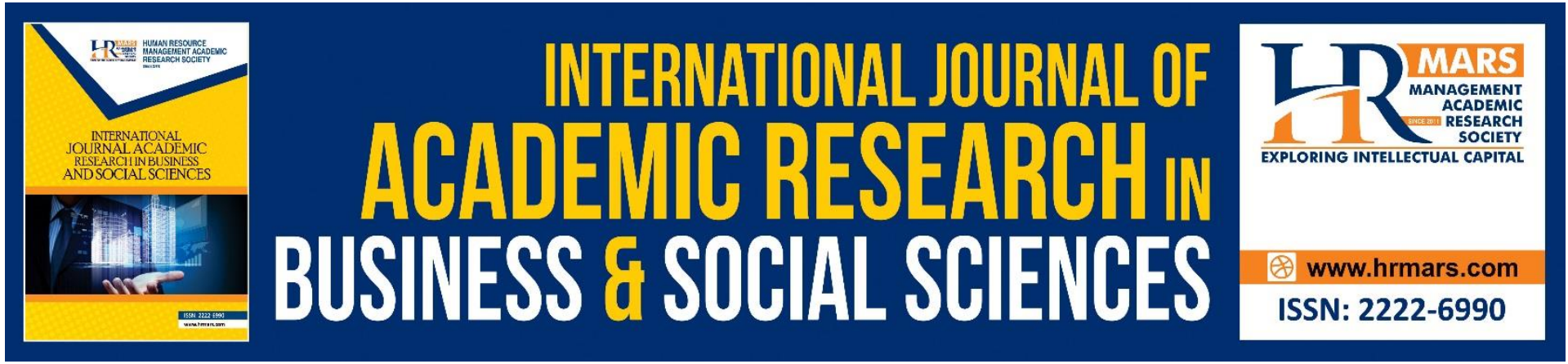

\title{
Stress and Coping Strategies in Public Speaking: Comparative Case Studies of Japanese and Malaysian Undergraduates
}

Ameiruel Azwan Ab Aziz, Ariff Imran Anuar Yatim, Nor Afifa Nordin, Nur Aqilah Norwahi

To Link this Article: http://dx.doi.org/10.6007/IJARBSS/v11-i6/10385

DOI:10.6007/IJARBSS/v11-i6/10385

Received: 11 April 2021, Revised: 13 May 2021, Accepted: 27 May 2021

Published Online: 20 June 2021

In-Text Citation: (Aziz et al., 2021)

To Cite this Article: Aziz, A. A. A., Yatim, A. I. A., Nordin, N. A., \& Norwahi, N. A. (2021). Stress and Coping Strategies in Public Speaking: Comparative Case Studies of Japanese and Malaysian Undergraduates. International Journal of Academic Research in Business and Social Sciences, 11(6), 1581-1591.

Copyright: @ 2021 The Author(s)

Published by Human Resource Management Academic Research Society (www.hrmars.com) This article is published under the Creative Commons Attribution (CC BY 4.0) license. Anyone may reproduce, distribute, translate and create derivative works of this article (for both commercial and non-commercial purposes), subject to full attribution to the original publication and authors. The full terms of this license may be seen at: http://creativecommons.org/licences/by/4.0/legalcode

Vol. 11, No. 6, 2021, Pg. 1581 - 1591

Full Terms \& Conditions of access and use can be found at http://hrmars.com/index.php/pages/detail/publication-ethics 


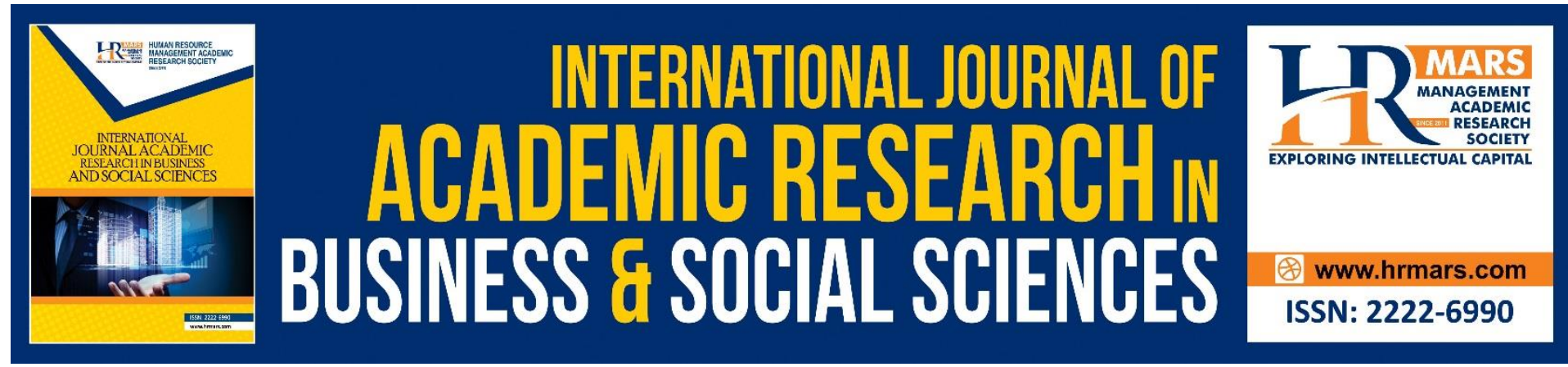

\title{
Stress and Coping Strategies in Public Speaking: Comparative Case Studies of Japanese and Malaysian Undergraduates
}

\author{
Ameiruel Azwan Ab Aziz, Ariff Imran Anuar Yatim, Nor Afifa \\ Nordin, Nur Aqilah Norwahi \\ Akademi Pengajian Bahasa, Universiti Teknologi MARA Cawangan Melaka \\ Email: ameirul@uitm.edu.my, ariffimran@uitm.edu.my, afifanordin@uitm.edu.my, \\ naqilahn@uitm.edu.my
}

\begin{abstract}
Public speaking competency is one of the core skills that is essential for personal and professional growth. Students who display effective public speaking skills are able to get their messages across while projecting confidence, clarity, and conviction which enhance their job prospects for future employability. Conversely, students' failure to cope with the stress faced in preparing for public speaking may affect their speaking effectiveness. This comparative case study explored the stress and coping strategies among Japanese and Malaysian undergraduates in two universities to understand the similarities, differences, and patterns across these two groups that share a common focus. Study participants were selected through a purposive sampling technique in which relevant data was collected using semistructured interviews. Data gathered were then analysed thematically to identify the stressors and coping strategies in public speaking across the two groups. Results indicate similar stressors experienced by participants which are external speech stress factors, resource deficit, and anticipatory speech anxiety in public speaking. Personal, social, and academic-oriented strategies were the participants' strategies to cope with the stress. These results suggest that similar stressors are faced by undergraduate students in performing public speaking, as well as and coping strategies used. This shows that the stress of public speaking is a prevalent occurrence and that institutional intervention can be developed by tertiary institutions to minimise its detrimental effects.
\end{abstract}

Keywords: Coping Strategies, Public Speaking, Stress

\section{Introduction}

Stress in public speaking, specifically among undergraduate students, has been extensively explored by researchers over the years (Zulkurnain \& Kaur, 2014; Evans, Clinton, Cookson, Brown \& Woods, 2017; Long, Yih \& Lin, 2019). This phenomenon has also been studied across different age groups, such as high school students (Katz, 2016) and working adults (Mellifont, Smith-Merry \& Scanlan et al., 2016). In addition, public speaking anxiety is a universally shared issue across different geographical divides as studies on this have been conducted in countries 
like France (Hua et al., 2016), Belgium (Casteleyn, 2019), Pakistan (Raja, 2017), Indonesia (Sutarsyah, 2017) and Malaysia (Miskam \& Saidalvi, 2019).

The mastery of public speaking skills ensures that students can convey their messages effectively and confidently. These skills are also highly valuable as the ability to conquer public speaking skills such as speaking with confidence, projecting controlled body language and presenting good enunciation and pronunciation could impress employers and enhance job prospects for professionalism and employability (Mousawa \& Elyas, 2015). However, public speaking anxiety (PSA) remains a persistent occurrence among undergraduate students despite continuous research over the years. Students' failure to cope with the stress faced in preparing for public speaking may lower their performance and negatively affect their ability to communicate with clarity and conviction in both academic and non-academic settings.

This research explores the stress and coping strategies faced in public speaking among undergraduate students in two universities (Japan and Malaysia) for a comparative study to identify the similarities, differences, and patterns across the two groups of students. The study focuses on the following research questions:

1. What are the stressors faced in preparing and performing in public speaking among undergraduate students?

2. What are students' strategies to cope with stress related to performing public speaking?

\section{Literature Review}

\section{Stress, Appraisal, and Coping}

One of the most significant cornerstones in stress research can be found in Lazarus and Folkman's (1984) theory of stress, appraisal, and coping. This theory posits that stress is a product of a transaction between a person (cognitively, physiologically, affectively, psychologically or neurologically) and his or her environment. Stress is experienced when a person perceives that the "demands exceed the personal and social resources the individual is able to mobilize." This transactional framework of stress is fundamentally different from earlier stress research (Selye, 1956) which views stress as a response or stimulus. Therefore, it focuses on cognitions and perceptions, or appraisals, that mediate the response to stressful events (Lazarus, 1999).

Within this framework, the appraisal theory defines an appraisal as the individual cognitions of a specific event or a stressor. According to Lazarus and Folkman (1984), cognitive appraisal occurs when a person considers two major factors that majorly contribute to his response to stress. These factors are the threatening tendency of the stress to the individual and the assessment of resources required to minimise, tolerate or eradicate the stressor and the stress it produces. These two factors form the basis of the two types of appraisal that happen simultaneously; primary appraisal and secondary appraisal. Primary appraisal happens when the individual evaluates an event or situation as a potential hazard to their well-being (Matthieu \& Ivanoff, 2006). In other words, the appraisal focuses on the magnitude of the event and whether it poses a threat to the individual. On the other hand, the secondary appraisal is related to the individual's evaluation of their ability to handle the event or situation. This evaluation is subjective to, but not necessarily after, the primary appraisal of the event or situation (Lazarus, 1999). It is suggested that after both primary and secondary appraisals of a stress-inducing situation are made, an individual will be able to move from thinking to action. 
In response to primary and secondary appraisals, a behaviour called coping takes place. Coping is defined as a process of "constantly changing cognitive and behavioural efforts to manage specific external and/or internal demands that are appraised as taxing or exceeding the resources of the person" (Lazarus \& Folkman, 1984). In this stage of the framework, coping strategies are employed based on their two forms: problem-focused coping and emotion-focused coping. Problem-focused coping strategies involve directing all efforts to handle distressing situations with task-oriented actions like gathering information, making decisions, resolving conflict, and acquiring necessary resources such as knowledge, skills, and abilities (Folkman \& Moskowitz, 2000). These strategies allow individuals to focus on the specific goals of the situations and align their behavioural responses to achieve them. Emotion-focused strategies, on the other hand, involve the practice of positive reappraisal to regulate stress. This process of cognitively reframing typically complex thoughts in a more positive light impacts the individual's evaluation of the difficult situation and helps them alter the interaction between perceived stress and its appraisal, facilitating better coping strategies (Lazarus, 1999).

\section{Public Speaking Anxiety}

Public speaking anxiety (PSA) is widely regarded as one of the most common social phobias. Language anxiety is elaborated by Horwitz et al (1986) as "a distinct complex of selfperceptions, beliefs, feelings, and behaviours related to classroom language learning arising from uniqueness of the language learning process" (p. 128). This is further divided into three categories: communication apprehension, test anxiety, and fear of negative evaluation to provide teachers with anxiety. Specifically, communication apprehension is defined as "a type of shyness characterised by the fear of or anxiety about communicating with people", test anxiety as "a type of performance anxiety stemming from a fear of failure," and fear of negative evaluation as "apprehension about other's evaluation, avoidance of evaluative situations and expectations that others would evaluate negatively" (Tercan \& Dikilitaş, 2015).

Several studies on speaking anxiety among students have been conducted over the years, specifically in the Malaysian setting. For instance, a study by Zulkurnain and Kaur (2014) revealed that the communication difficulties experienced by the group of university students were consistent with four categories of communication difficulties stated by Dornyei and Scott (1997) which are namely; resource deficit, processing time pressure, own-performance problem and other-performance problems. The study also identified limited English vocabulary as being the most common barrier. Next, another study by Miskam and Saidalvi (2019) adapted the Foreign Language Speaking Anxiety Scale (FLSAS) (Balemir, 2009; Huang, 2004) to measure the level of undergraduate students' speaking anxiety. It was found that a majority of these students had a moderate level of speaking anxiety. The dominant factor contributing to this issue was communication apprehension for high and moderate anxiety learners, while test anxiety was observed in low anxiety learners. Another noteworthy study on this issue can also be observed in Long, Yih, and Lin (2019) on undergraduate students from two public institutions of higher learning in Sarawak. While this study reported that the students generally experienced an average of speaking anxiety, which was a similar finding to Miskam and Saidalvi's (2019) study, one interesting observation was that female undergraduate experienced a significantly higher level of speaking anxiety compared to their male counterparts.

Research on public speaking anxiety (PSA) among students remains pertinent as this affective variable plays a significant factor in predicting their speaking performance. While a 
reasonable amount of anxiety can lead to the students being more motivated and focused in preparing for a speaking task, students' excessive anxiety may lead to them having low achievement levels due to their inability to regulate their stress effectively (Tercan \& Dikilitaş, 2015).

\section{Methodology}

The present study investigates 24 undergraduate students from a Malaysian and a Japanese university using a qualitative case study approach. Yin (1994, p.51) defined a case study as "an empirical inquiry that investigates a contemporary phenomenon within its real-life context, especially when the boundaries between phenomenon and context are not clearly evident". Yin (1994) suggested the case study as a particular style of educational research that may be appropriate for investigating the concept of public speaking-related stress and anxiety.

In this study, purposive sampling was utilized to select prospective participants. The participant selection was to select undergraduate students who were undergoing a public speaking course in English at the time of data collection. All 24 participants were solicited during formal and informal meetings of the course. The search for prospective participants ended when the data reached saturation level, in which there was sufficient information to replicate the study and no new data emerged. The data gathered was able to answer the research questions, and the ability to gain additional new information had been accomplished, and further coding was no longer feasible (Glesne \& Peshkin, 1992).

\section{Data Analysis}

In this study, participants' views, opinions and meaningful responses contain detailed and descriptive responses. Semi-structured interviews were used as a primary data collection method to illustrate the experiences gained in fulfilling a public speaking task. The recordings were transcribed, and field notes were examined immediately after the session to ensure accurate analysis. Observations were also conducted to gain insider's perspectives of the phenomenon under study as another source for triangulation of data, increasing the study's trustworthiness and filling any gaps between what research participants narrated through interviews and what happens. The researchers have attempted to acknowledge what had been seen and noted in actual reality. Reflections were done at the end of each session as an addition to the field notes. Some of the data obtained in the observations were also used as talking points in the post-observation interviews.

Data were then analysed using thematic analysis. Thematic analysis is a method to identify, analyse, and report data themes (Boyatzis, 1998). This study uses inductive thematic analysis in which the themes identified are closely related to the data itself (Patton, 1990). Inductive thematic analysis tends to analyse themes in the data in detail, without giving attention to the related themes from the findings in previous research.

\section{Results}

\section{Public Speaking Stress}

The interview sessions revealed that all 24 participants from Malaysia and Japan felt a sense of fear in public speaking. The analysis shows three main themes of stressors that lead to public speaking stress: external speech stress factors, resource deficit, and anticipatory speech anxiety. 


\section{External Speech Stress Factors \\ Social-related Anxiety}

The fear of being assessed while speaking in public was mentioned most by Malaysian participants. The fear includes being the centre of attention, evaluation of their speaking ability. In contrast, only one Japanese participant remarked that being assessed of his language ability contributes to the stress in English public speaking. The result shows Malaysian participants concern more on social-related anxiety compared to Japanese participants.

Another concern among Malaysian participants is the audience's reaction. The participants expressed that they would get anxious if they felt that their audience was getting bored of their presentations. Participants from both countries agreed that the nervousness was due to speaking publicly and perceived facial audience expression. Other than that, the tendency to compare themselves to other speakers has also contributed to the factor for the audience's reaction.

\section{Situational-related Anxiety}

The fear of becoming forgetful and being the last speaker during public speaking was acknowledged mainly by Malaysian participants. The participants were concerned about forgetting their lines or scripts or losing ideas in the middle of the presentations. Meanwhile, Japanese participants' stress factors depended on the audience, place, and situation affect their confidence to speak publicly.

\section{Resource Deficit Low English Proficiency}

As non-native speakers, having low English proficiency was expressed by participants from both countries as a factor that contributed to their lack of confidence in public speaking. It was particularly due to limited vocabulary and mispronunciation of words for Malaysian participants, while Japanese participants felt that mastery of the English language is challenging.

\section{Preparation Time}

Preparations prior to public speaking also determine participants' readiness in their presentations where participants, as their stress factors mentioned time and technical issues. It is interesting to learn that both nations' participants responded that insufficient preparation time and lack of preparation affect their ability to present well. The participants stated that lack of preparation for his speech would cost him to feel nervous during public speaking. They also mentioned preparation time as one of the fear factors in public speaking. Script memorisation was an important step before the presentation.

\section{Technical Preparation}

When it comes to technical preparations, it is found that Japanese participants felt more stressed compared to Malaysian students, and the factors included were the writing of the speech, initiating the speech, and getting unfamiliar and uninteresting speech topics. 


\section{Anticipatory Speech Anxiety}

\section{Self-conscious Issues}

The participants also reported anticipatory speech anxiety. It then was divided into two categories; self-consciousness and confidence issues. More Malaysian participants feared being in the limelight compared to Japanese participants. Apart from that, they were also concerned about being perceived as stupid and confused and feeling shy.

\section{Confidence Issues}

Participants from both countries also mentioned issues in self-confidence. While most Malaysian participants concerned about making mistakes, Japanese participants expressed that their lack of confidence level was a fear factor in public speaking.

\section{Public Speaking Stress Coping Strategies}

In coping with the stress faced, the Japanese and Malaysian students shared several coping strategies to deal with public speaking-related stress: personal, social, and academic-oriented strategies.

\section{Personal coping strategies Cognitive}

Interestingly, most participants used a self-persuasion strategy to overcome speaking anxiety, where the former mentioned this the most in the interview. Concerning that, being optimistic was dubbed to be crucial by the participants in coping with public speaking stress. Additionally, they preferred to be in solitude before the session to search for tranquillity while

\section{Physical}

The data exhibits that more Japanese participants practised physical activities to overpower public speaking anxiety. Activities like listening to music, playing sports, reading books, and watching movies or videos helped them ease stress. Interestingly, several Malaysian participants opted for singing as a coping strategy.

\section{Behavioural}

Besides overcoming anxiety cognitively and physically, both Malaysian and Japanese students opted for behavioural actions such as taking deep breaths, sputtering, holding on to handphones or stress-reliever tools, eating and sleeping.

\section{Social Coping Strategies \\ Peer support}

From the interviews, participants from both countries, particularly Malaysians, expressed that peer support plays a major role in easing their anxiety by talking to their friends and giving them supportive reactions.

\section{Instructor Support}

The participants also sought for instructor's support, and it is believed that just like getting peer support, receiving supportive reactions from the instructors helped provide comfort to their public speaking anxiety. Several participants specifically mentioned that they would directly talk to their professors whenever they need help. 


\section{Academic-oriented Coping Strategies Speech Preparation}

The interviews revealed that speech preparation, which included preparing scripts and presentation slides, helped reduce public speaking anxiety. More Malaysian participants mentioned this strategy than only one Japanese participant stated that the task would not be difficult for him with sufficient preparation time. Additionally, participants disclosed that experience allowed them to perform better in oral presentations.

\section{Speech Practice}

Besides preparing for the scripts, participants noted that frequent practices were also the key to overcoming public speaking anxiety. More than half of the Japanese participants expressed that frequent practices helped them to have better stress management. A few Malaysian participants felt the same, too.

\section{Speech Delivery}

Establishing eye contact with audiences appeared to be used by Japanese and Malaysian students as a coping strategy in public speaking stress. Other strategies that also involved the audience would be interacting with them, using humor, and attracting their attention.

\section{Discussion}

This study aimed to investigate the factors that lead to public speaking anxiety in Japanese and Malaysian students and their coping mechanisms. Oral assessment has been a norm in courses and is made compulsory. Even though this practice has long been integrated into schools, the participants admitted to feeling stressed concerning public speaking. This has frequently caused students to avoid speaking in English even outside of their classroom (Sadighi \& Dastpak, 2017).

The results show that students would feel very stressed when their instructors assessed them, which affected the way they present their speech. This is probably related to fear of negative evaluation, leading them to obtain lower marks for the assessment (Akkakoson, 2016). Apart from their instructors, they were also worried the audience might judge their appearance and stage presence. They worried about appearing stupid and confused in front of the audience, especially because they became the centre of attention when they speak. This further strengthens Lazarus and Folkman's theory where they stated that whenever an individual experience a situation where he is expected to provide more than what he could, he would feel stressed out. Students' confidence level also played an important part in giving practical public speaking sessions. According to the results, students who felt they lacked in it would end up with speech anxiety. It is also interesting to note that Japanese students were not affected by social-related anxiety than Malaysian students. Nevertheless, it is evident that the fear of being assessed by others has a major impact in inducing participants' public speaking anxiety.

Low English proficiency level was also considered to influence students' anxiety in public speaking, mainly students from Malaysia. Students admitted that limited vocabulary caused them to be anxious as they would be lost at words and ended up using too many fillers while speaking, hence, interrupting the flow of their speech. Akkakoson (2016) stated that students would have difficulty understanding others or expressing their viewpoints without sufficient vocabulary. Since the participants are non-native speakers, they may find it challenging to construct complete sentences without the help of pre-written scripts. 
However, at most times, instructors prohibit their students from relying too much on the scripts to prevent students from reading aloud instead of demonstrating their speaking skills. This could also trigger another element in public speaking anxiety: mispronunciation of words due to limited vocabulary, which eventually deemed poor communication skills. Through the analysis, it could be seen that more Malaysian students were worried about their English proficiency level than Japanese students. Nevertheless, a few Japanese students mentioned that making mistakes caused them to be anxious in public speaking. A student also confessed that English is a complex language to learn and practice, which is understandable since it is deemed a foreign language in the land of the rising sun. In fact, Japan is placed in the "low proficiency" band after the country dropped to 53rd place in global English proficiency, and they are currently refining their English educational curriculum in schools (Margolis, 2020). Thus, this further explains why English proficiency was not a major factor for Japanese students because the language is not perceived as of the utmost importance in the country's socio-economic status.

Besides English proficiency level, preparation time and technical preparation were also part of resource deficit, contributing to public speaking anxiety. It can be acknowledged that students were aware of the significance of being well-prepared before any public speaking sessions. Insufficient preparation time, which might be due to other assignments or poor time management, can also become a source of anxiety. There were possibilities that students would wait until the eleventh hour to prepare for the task. As to defend this outlook, students also listed speech writing and unfamiliar topic to be the stressors. Unless it is a public speaking competition, instructors typically provide a stipulated period for students to prepare for their assessments. Technical issues like unfamiliar topics and incomplete slides would not emerge as stress factors should the students have better time management skills.

On the other hand, what is interesting in the findings is the similarities in the strategies adopted by students from both countries to overcome public speaking stress. The most mentioned coping strategy is through self-persuasion or self-talk. This showed that students were self-conscious and aware of their weaknesses. Therefore, they employed this strategy to improve their speaking skills and complete the speech. This strategy was also found in a study by El-Sakka (2016), where self-talk has proven to reduce speaking anxiety in forty English-major students in an Egyptian university. Another coping strategy involved support mainly from friends and instructors, which is not surprising as these are the people that students usually refer to when it is related to educational matters. Mistakes are unavoidable for language learners, but when instructors tolerate the errors and assist students, it will "release pressure" in public speaking (He, 2017). It can be concluded that just talking to them or seeing their positive reactions helped students feel calmer and more confident to complete any oral activities.

Earlier, speech preparation was one of the main factors inducing public speaking anxiety among students from Japan and Malaysia. Interestingly, it was also found to be among the most mentioned coping strategy but by having proper preparation of the speech and frequent practices. A similar result was also found in a study by Rafieyan and Yamanashi (2016) regarding prior preparation. This further supports Lazarus and Folkman's problemfocused coping theory, where a person can control a difficult situation once the source of the problem is identified. It is worth noting that students were aware of their limitations in public speaking, which led to anxiety. However, they were also attentive in their coping strategies in order to improve their skills. 


\section{Conclusion}

The triangulation of data postulates clearly that the participants acknowledged the presence of stress in fulfilling public speaking tasks. The researchers have identified external speech stress factors, resource deficit, and anticipatory speech anxiety as the stressors that significantly influence their performance in public speaking. Nevertheless, the results also revealed that all participants in the study appraised the stress cognitively to seek possible solutions. Personal, social, and academic-oriented strategies were used as coping mechanisms to manage and alter the stress or regulate the response to the stress.

These findings advance the understanding of English education in tertiary education by providing insights into the subject, and context-specific descriptions of the lived experiences and perceptions of the participants. The understanding gained could offer recommendations for changes in educational practices to improve, thus positively impacting students' performance and university reputation.

\section{References}

Akkakoson, S. (2016). Speaking anxiety in English conversation classrooms among Thai students. Malaysian Journal of Learning and Instruction, 13(1), 63-82.

Balemir, H. S. (2009). The Sources of foreign language speaking anxiety and the relationship between proficiency level and degree of foreign language speaking anxiety. (Unpublished master's thesis). Bilkent University Ankara.

Boyatzis, R. (1998). Transforming qualitative information: Thematic analysis and code development. Thousand Oaks, CA: SAGE.

Casteleyn, J. (2019). Playing with improv(isational) theatre to battle public speaking stress. Research in Drama Education: The Journal of Applied Theatre and Performance, 24(2), 147-154.

Dornyei, Z., \& Scott, M. L. (1997). Communication Strategies in a Second Language: Definitions and Taxonomies. Language Learning, 47, 173-210.

El-Sakka, S. M. (2016). Self-regulated strategy instruction for developing speaking proficiency and reducing speaking anxiety of Egyptian university students. English Language Teaching, 9(12), 22-33.

Evans, J. F., Clinton, E., Cookson, G., Brown, S., \& and Woods, D. (2017). The Stress of Public Speaking Increases Cortisol Levels in Undergraduates: Is increased preparation really the best remedy? In Vivo, 38(2).

Folkman, S., \& Moskowitz, J. T. (2000). Positive affect and the other side of coping. American Psychologist, 55, 647-654.

Glassman, L. H., Forman, E. M., Herbert, J. D., Bradley, L. E., Foster, E. E., Izzetoglu, M., \& Ruocco, A. C. (2016). The effects of a brief acceptance-based behavioral treatment versus traditional cognitive-behavioral treatment for public speaking anxiety: An exploratory trial examining differential effects on performance and neurophysiology. Behavior Modification, 1-29.

Glesne, C., \& Peshkin, A. (1992). Becoming Qualitative Researchers: An Introduction. White Plains, NY: Longman.

He, D. (2017). How to cope with foreign language speaking anxiety effectively? The case of university students in China. Electronic Journal of Foreign Language Teaching, 14(2).

Horwitz, E. K. (1986). Foreign language classroom anxiety. The Modern Language Journal, 70(2), 125-132. 
Huang, H. ((2004)). The relationship between learning motivation and speaking anxiety among EFL non-English major freshmen in Taiwan. (Unpublished master's thesis). The Chaoyang University of Technology.

Katz, D. A. (2016). Adolescent stress reactivity and recovery: Examining the relationships between emotion regulation and the stress response with a school-based group public speaking task.

Lazarus, R. S. (1984). Stress, Appraisal, and Coping. New York: Springer Publishing Company.

Lazarus, R. S. (1999). Stress and Emotion: A New Synthesis. New York: Springer Publishing Company.

Long, K. L., Yih, Y. J., \& Lin, S. S. (2019). Undergraduates' Speaking Anxiety in English as Second Language (ESL) Classrooms. International Journal of Service Management and Sustainability, 4(1), 25-39.

Margolis, E. (2020). Japan doesn't want to become another casualty of English. Retrieved from https://foreignpolicy.com/2020/05/26/japan-doesnt-want-to-become-anothercasualty-of-english/

Matthieu, M., \& Ivanoff, A. (2006). Using stress, appraisal, and coping theories in clinical practice: Assessments of coping strategies after disasters. Brief Treatment and Crisis Intervention, 6(4), 337-348.

Mellifont, D., Smith-Merry, J., \& Scanlan, J. N. (2016). Pitching a Yerkes-Dodson curve ball?: A study exploring enhanced workplace performance for individuals with anxiety disorders. Journal of Workplace Behavioral Health, 31(2), 71-86.

Mousawa, D. T., \& Elyas, T. (2015). Presentation as employability soft skill to ESP learners in the English Language Institute at King Abdulaziz University. Journal of Language Teaching and Research, 6 (5), 1058-1062.

Patton, M. Q. (1990). Qualitative Evaluation And Research Methods (2nd ed). Newberry Park: Sage.

Rafieyan, V., \& Yamanashi, K. (2016). Discovering factors of foreign language speaking anxiety and coping strategies. Journal for the Study of English Linguistics, 4(1), 111-125.

Raja, F. (2017). Anxiety Level in Students of Public Speaking: Causes and Remedies. Journal of Education and Educational Development, 4(1), 94-110.

Sadighi, F., \& Dastpak, M. (2017). The sources of foreign language speaking anxiety of Iranian English language learners. International Journal of Education and Literacy Studies, 5(4), 111-115.

Selye, H. (1956). The Stress of Life. New York: McGraw Hill.

Sutarsyah, C. (2017). An analysis of student's speaking anxiety and its effect on speaking performance. Indonesian Journal of English Language Teaching and Applied Linguistics, Vol. 1(2), 143-152.

Tercan, G., \& Dikilitaş, K. (2015). EFL students' speaking anxiety: A case from tertiary level students. ELT Research Journal, 4(1), 16-27.

Yin, R. K. (1994). Case study research: Design and methods (2nd ed). Thousand Oaks, CA: Sage. Zulkurnain, N., \& Kaur, S. (2014). Oral English communication difficulties and coping strategies of Diploma of Hotel Management students at UiTM. 3L: Language, Linguistics, Literature $^{\circledR}, 20(3)$. 